\title{
COMMON ECTOMYCORRHIZAL NETWORKS MAY MAINTAIN MONODOMINANCE IN A TROPICAL RAIN FOREST
}

\author{
Krista L. McGuire ${ }^{1}$ \\ 830 North University Avenue, Department of Ecology and Evolutionary Biology, University of Michigan, \\ Ann Arbor, Michigan 48109 USA
}

\begin{abstract}
Most tropical rain forests contain diverse arrays of tree species that form arbuscular mycorrhizae. In contrast, the less common monodominant rain forests, in which one tree species comprises more than $50 \%$ of the canopy, frequently contain ectomycorrhizal (ECM) associates. In this study, I explored the potential for common ECM networks, created by aggregations of ECM trees, to enhance seedling survivorship near parent trees. I determined the benefit conferred by the common ECM network on seedling growth and survivorship of an ECM monodominant species in Guyana. Seedlings with access to an ECM network had greater growth (73\% greater), leaf number (55\% more), and survivorship (47\% greater) than seedlings without such access, suggesting that the ECM network provides a survivorship advantage. A survey of wild seedlings showed positive distance-dependent distribution and survival with respect to conspecific adults. These experimental and survey results suggest that the negative distance-dependent mechanisms at the seedling stage thought to maintain tropical rain forest diversity are reversed for ECM seedlings, which experience positive feedbacks from the ECM network. These results may in part explain the local monodominance of an ECM tree species within the matrix of high-diversity, tropical rain forest.

Key words: common mycorrhizal network; Dicymbe corymbosa; distance dependence; ectomycorrhizal association; Guyana, monodominance; seedling survival; tropical rain forest diversity.
\end{abstract}

\section{INTRODUCTION}

Although tropical rain forests have the highest documented tree diversity per area of any ecosystem (Valencia et al. 1994), large stands of low-diversity, monodominant rain forest also occur, in which one tree species comprises $>50 \%$ of the overstory stems and/or basal area (Connell and Lowman 1989, Hart 1990, Torti and Coley 1999). These monodominant forests occur in all tropical regions, and the characteristics that enable these species to dominate areas of otherwise diverse rain forest have yet to be fully understood (Makana et al. 2004). A consistent relationship between monodominance and ectomycorrhizal (ECM) associations has led to the suggestion that the ECM mutualism may contribute to the success of monodominant trees (Hart et al. 1989). This is in part based on the observation that most other tropical trees form arbuscular mycorrhizal (AM) associations (Janos 1983, 1985). The ECM mutualism alone cannot explain all tropical monodominance (Martijena and Bullock 1994, Torti and Coley 1999, Torti et al. 2001), but the rarity of the ECM habit in non-monodominant tropical trees, and the presumed advantages of ECM fungi in low nutrient soils common in the tropics (Buscott et al. 2000), suggests that ECM

Manuscript received 5 August 2005; revised 20 March 2006; accepted 21 March 2006. Corresponding Editor: G. S. Gilbert. For reprints of this Special Feature, see footnote 1, p. 539.

${ }^{1}$ E-mail: mcguirek@umich.edu associations are not inconsequential to the success of these trees.

One way by which ECM fungi may contribute to the higher survivorship of ECM seedlings by linking seedlings to larger trees via common ECM networks (Nara 2006). The specific benefits of these connections for ECM seedlings may include the net movement of $\mathrm{N}$ (Arnebrant et al. 1993, He et al. 2004), P (Finlay and Read 1986a), and photosynthate (Brownlee et al. 1983, Finlay and Read 1986b, Simard et al. 1997) between seedlings. These transfers may also occur from parent trees to conspecific seedlings, but this has not yet been tested in a field setting. Seedlings may benefit from more rapid and extensive ECM colonization, which would provide greater access to soil nutrient pools and water (Alexander et al. 1992, Dickie et al. 2002, Onguene and Kuyper 2002). Seedling advantages resulting from these transfers depend on the extent to which seedlings are limited by nutrients and light. A related benefit would arise if larger trees maintain the $\mathrm{C}$ cost required for the mycorrhizal network (Newman 1988). Mycorrhizal fungi can receive $57-100 \%$ of their C from canopy adults (Hogberg et al. 1999), so seedlings could potentially become mycorrhizal without expending their own C. In the extreme case of sparse or no ECM colonization, it has been demonstrated that some ECM species will not survive (Vozzo and Hacskayl 1971). Thus, for obligately mycorrhizal species, more rapid 
mycorrhization may decrease mortality risks in newly germinated, vulnerable seedlings.

The ability of some ECM fungi to form extensive belowground networks large enough to link neighboring ECM trees together is supported by both laboratory (Finlay and Read 1986b, McKendrick et al. 2000, Wu et al. 2001) and field studies (Bergemann and Miller 2002, Kennedy et al. 2003, Simard and Durall 2004). It should be noted, however, that some mature ECM genets may be small in size (Redecker et al. 2001), so not all ECM fungi may have the ability to form extensive common ECM networks. Thus, the specific ECM fungal assemblages may be important for the existence of common ECM networks in the field. Functioning of the common ECM network in the field is poorly documented, and most studies investigating common ECM networks have been conducted in temperate ECM systems (Booth 2004, Simard and Durall 2004). The role of common ECM networks in tropical forest dynamics is limited to few field studies with disparate methodologies. These methodologies include the use of PVC pipes to exclude seedling roots from access to the ECM network (Onguene and Kuyper 2002) and seedling transplantation away from ECM adults (Alexander et al. 1992, Newbery et al. 2000). The limitation to the use of PVC pipes to exclude seedlings from the ECM network is that nutrient and/or water transport may be significantly altered inside of the pipes. In the seedling transplantation experiments, the absence of the ECM network is not guaranteed and microsite differences in the nonECM forest areas may confound experimental results. Physical barriers that exclude plant roots from the ECM network, but allow water and nutrient transport are needed to better explore the importance of common ECM networks in these tropical ECM forests (Robinson and Fitter 1999).

If ECM networks enhance seedling survival, it can be predicted that positive distance-dependent seedling survival will be observed in these systems. This prediction is based on the assumption that seedlings should experience greater survival near to parent trees where there is increased access to a common ECM network. Over time, this positive distance dependence will maintain a low-diversity, monodominant rain forest, by promoting conspecific aggregation of ECM trees. This is contrary to negative and/or neutral distance-dependent processes, which are thought to be key components of the maintenance of tropical tree diversity (Wright 2002, Leigh et al. 2004). Negative distance dependence, a component of the JanzenConnell hypothesis, results in reduced conspecific seed and seedling survival near reproductive adults due to preferential foraging by seed predators and herbivores, and increased pathogen infection (Janzen 1970, Connell 1971). Heterospecific seedlings are left to colonize areas where the conspecific seeds and seedlings have died, and diversity is maintained over time (Harms 2000). Highdiversity rain forests also are maintained in models of neutral distance dependence, in which mortality is random and seed and/or seedling survival is not affected by the presence of conspecific adults (Hubbell and Foster 1986, Chave 2004). Thus, in order to maintain monodominant rain forest, assumptions of neutral and negative distance-dependent models must be violated. Positive distance-dependent ECM seedling survival due to the benefits conferred by the common ECM network, is a plausible mechanism that provides such a conceptual framework to maintain monodominant rain forest.

In this study, I experimentally tested whether seedlings of an ECM tree species that forms monodominant stands, have increased survivorship when they are connected to the common ECM network. The related prediction that wild seedlings should exhibit positive distance-dependent survival (reverse of the Janzen/Connell hypothesis) was also tested.

\section{Methods}

This study was conducted in tropical rain forest in central Guyana $\left(5^{\circ} 18^{\prime} \mathrm{N}, 59^{\circ} 54^{\prime} \mathrm{W}\right.$, elevation $\left.720 \mathrm{~m}\right)$, in which Dicymbe corymbosa Spruce ex. Benth. (Caesalpiniaceae) forms large clumps of monodominant rain forest comprising $70-90 \%$ of the canopy (Henkel 2003). This species exhibits mast fruiting at irregular intervals every seven to 10 years (Zagt and Werger 1997). This study was initiated during such a masting event in 2003. Fruits of $D$. corymbosa are explosively dehiscent and seeds fall within several meters of the mother tree's crown. Seeds germinate within one to three days of falling to the ground and have no dormancy (personal observation). Monodominant patches of $D$. corymbosa occur within matrices of high-diversity, mixed rainforest, and D. corymbosa has not yet been documented as a solitary individual within the mixed forest (Ter Steege et al. 2000, Henkel 2003). There are no apparent differences in soil parameters or topography between forest types (K. L. McGuire, unpublished data; also see Henkel 2003). Dicymbe corymbosa forms ECM associations, whereas 139 of 142 (98\%) surveyed species from 6 ha of experimental plots form AM associations, but not ECM associations (K. L. McGuire, unpublished data), thereby providing an ideal system in which to investigate mechanisms of ECM monodominance.

To determine the influence of ECM networks on monodominant seedling survival, $D$. corymbosa seeds were germinated in mesh pots that either restricted or enabled their access to the common ECM network. Seedling growth and survival were monitored in response to ECM network exclusion. To exclude seedling access to the common ECM network, seeds were planted in nylon mesh pots with $0.45 \mu \mathrm{m}$ diameter pores. This pore size is small enough so that roots and hyphae are prevented from passing through the mesh in either direction (in or out). To enable seedling access to the ECM network, seeds were germinated in a mesh pot with $20 \mu \mathrm{m}$ diameter pores. This pore size is large enough to allow passage of fungal hyphae, but small 
enough to restrict root passage. A third treatment, in which seeds were planted directly on the forest floor, was also included to control for the effect of the mesh pots. Before placing the seed on the ground in this treatment, soil dug up and replaced as it was when planting the mesh pots. This was intended to keep initial soil disturbance constant across treatments. Seeds of the AM species Eschweilera sagotiana Miers (Lauraceae), a tree common to both mixed and monodominant forests, were also planted as a negative control. These seeds were planted in the same treatments, but were readily removed from the pots or predated in situ. The final sample size was too small for analysis, so this species will not be discussed further.

Dicymbe corymbosa seeds were collected from the floor of the monodominant forest and planted $1.5 \mathrm{~m}$ from the base of the adult tree in a randomly selected direction and a treatment was randomly assigned. Each treatment was replicated 16 times, for a total of 48 experimental units. The mesh pots had dimensions 30 $\mathrm{cm}$ width by $40 \mathrm{~cm}$ depth (volume $706.9 \mathrm{~cm}^{3}$ ). These dimensions correspond to $10 \mathrm{~cm}$ greater than the maximum root width and length of 25 pre-existing seedlings on the monodominant forest floor. The age of the pre-existing seedlings was at least five years since the last masting event in this system occurred in 1998 (Zagt and Werger 1997). Designing the mesh pots around the dimensions of pre-existing seedling roots was done to eliminate potential cage effects that could occur if roots became crowded inside the pots after one year of the experiment. Sufficient overhang of the mesh above the organic layer was provided at the top of each mesh pot over to prevent growth of the common ECM network into the pot from above.

Three D. corymbosa seeds were planted in each pot and allowed to grow for one month, at which time the seedlings were thinned to one per pot. The percentage of ECM colonization was measured on the thinned seedlings (total of 73 seedlings) to determine whether or not the treatments had an effect on initial mycorrhizal colonization. A one-way ANOVA was used for this analysis. The remaining 48 seedlings were allowed to grow for one full year, after which they were harvested. The response variables measured were seedling survival, mean height of surviving seedlings and number of leaves on surviving seedlings after one year. Seedling survival was analyzed using a contingency table with Fisher's exact test, and pairwise exact tests were run for each combination of treatments. Mean height and leaf number of surviving seedlings after one year were analyzed using separate one-way ANOVA analyses with Tukey adjustments for post hoc comparisons. Data met the assumptions for homogeneity of variances and normality of residuals. The percentage of ECM colonization was also quantified for all surviving seedlings in the same manner for thinned seedlings and a one-way ANOVA was used to analyze colonization in response to treatment. All statistical analyses for the mesh experiment were run using SPSS 11 software (SPSS, Chicago, Illinois, USA).

To assess whether or not D. corymbosa seedlings exhibited positive or negative distance-dependent survival, a wild seedling survey was conducted in transitional forest, where the monodominant forest quickly transitions to mixed (this transition occurs within $50 \mathrm{~m}$ ). At this transition, an obvious line of D. corymbosa adults forms the edge of the monodominant forest. Starting from this edge six transects $(4 \times 25 \mathrm{~m})$ were surveyed, three of which were oriented toward the mixed forest and three of which were oriented toward the monodominant forest (see Appendix). Each transect began at the base of an adult $D$. corymbosa tree at the edge of the monodominant forest. Adults representing the edge of the monodominant forest were randomly selected, and all transects were at least $1 \mathrm{~km}$ from each other. In 2003, all D. corymbosa seedlings inside the transects were tagged at the base with thin metal wire and numbered aluminum tags (811 seedlings total). For each tagged seedling, distance from the edge of the transition zone and height were recorded. The initial distribution of seedlings was assessed as a function of distance from the edge of the transition zone using a linear regression model separately for each forest type. This was followed by an ANCOVA to compare the slopes of the regression lines. Data were binned into $1 \mathrm{~m}$ distance categories. In 2004, seedlings were re-surveyed to assess survival and change in height as a function of distance from the edge of the monodominant patch. Height in 2004 was only measured on surviving seedlings. For each seedling, the probability of mortality as a function of distance from the transition zone was assessed using a binary logistic regression model with generalized estimating equations used to account for clustering due to transect structure. Change in height was analyzed as a function of distance from the edge with a linear mixed model with random effect included for each transect. Statistical analyses for the seedling transects were run with SAS 9.1.3 (SAS Institute 2005).

\section{ReSUlts}

After one year, seedlings excluded from the common ECM network in the fine mesh treatment had significantly reduced survival compared to seedlings in the coarse mesh treatment $(P=0.037)$ and seedlings with no mesh treatment $(P=0.016)$. Seedling survival in the coarse mesh treatment was not significantly different than survival in the no mesh treatment $(P>0.99$; Fig. 1A). Mean seedling height of the surviving seedlings in the fine mesh treatment was significantly lower than in the coarse mesh treatment $\left(F_{2,22}=4.901, P=0.016\right)$ and the no mesh treatment $(P=0.033)$. Mean seedling height was not significantly different between the coarse mesh treatment and the no mesh treatment $(P=0.877$; Fig. 1B). Final leaf numbers of the surviving seedlings were also significantly smaller in the fine mesh treatment 

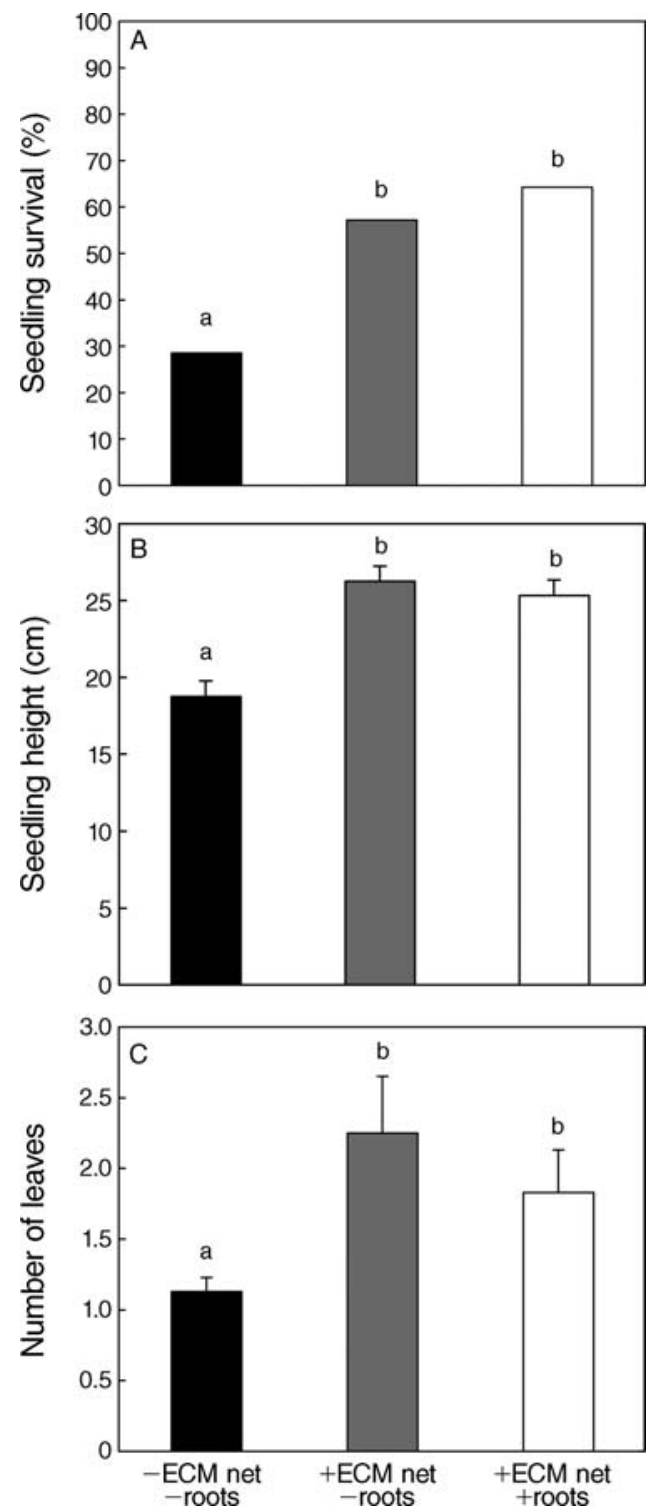

FIG. 1. (A) Survival, (B) height, and (C) number of leaves across treatments for Dicymbe corymbosa seedlings after one year. Dark bars represent the fine mesh treatment where common ECM net access and root passage were restricted, gray bars represent the coarse mesh treatment where access to the common ECM net was permitted but root passage was restricted, and white bars represent the control treatments (no mesh) where ECM net and root passage were both permitted. Error bars represent + SE. Bars with different letters indicate significant differences between means of $D$. corymbosa seedlings across treatments $(P \leq 0.05)$. Each treatment was replicated 16 times for a total of 48 experimental units.

compared to both the coarse mesh $\left(F_{2,22}=7.601, P=\right.$ $0.002)$ and no mesh $(P=0.038)$ treatments (Fig. 1C).

ECM structures were observed on all seedlings thinned out after the first month from the mesh pots. Percent initial colonization was near $100 \%$ on all seedlings, and there were no significant differences in percentage of initial colonization between treatments
$\left(F_{2,70}=0.574, P=0.566\right)$. Likewise, there were ECM structures observed on all surviving seedlings after one year. The percentage of colonization after one year was also near $100 \%$ on surviving seedlings, and this did not vary between treatments $\left(F_{12,12}=0.893, P=0.576\right)$.

In transects moving from the edge of the monodominant forest toward the mixed forest, seedling distributions following the 2003 mast had a negative overall relationship with a positive quadratic term (Fig. 2; $P<$ $0.001)$. This relationship accounted for $75 \%$ of the variance in seedling distributions after the mast. Seedling distribution in transects moving from the edge toward the monodominant forest had a slightly negative overall relationship, but this was not significant in relation to distance from the edge $(P=0.71$; Fig. 2 A).
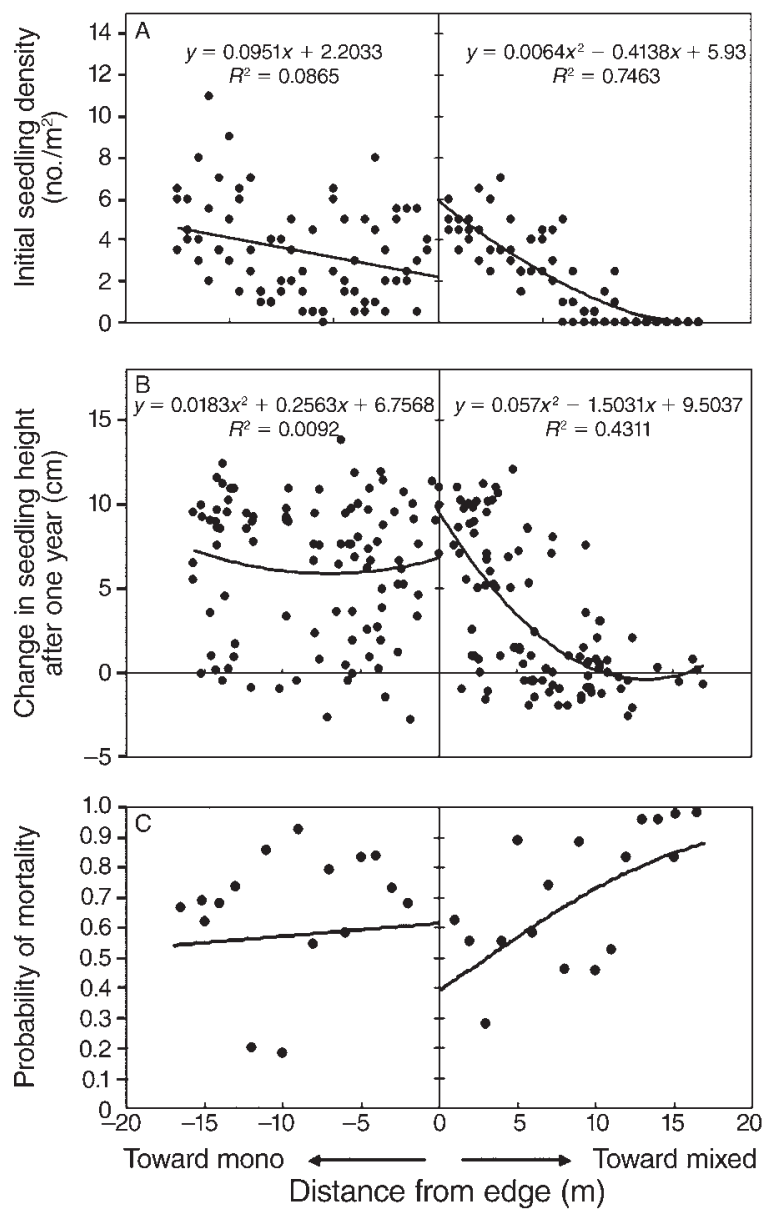

FIG. 2. The relationships between (A) initial D. corymbosa seedling distribution following the mast in 2003, (B) average seedling height of surviving D. corymbosa seedlings after one year, and (C) probability of $D$. corymbosa seedling mortality relative to distance from the edge for transects moving toward the monodominant forest ("toward mono") and the mixed forest ("toward mixed"). In total, 811 seedlings were initially tagged. Data were binned into 1-m intervals to plot proportional mortality (C), and probability of mortality predictions were superimposed on the actual data. The zero line represents the last adult Dicymbe corymbosa individual at the transitional zone. 
The probability of seedling mortality after one year was significantly explained by distance from the edge of the monodominant forest in transects moving toward the mixed forest $(P<0.001$; Fig. 2C). A total of 238 seedlings survived after one year. In contrast, seedling mortality after one year in transects moving toward the monodominant forest was not significantly explained by distance from the edge ( $P=0.48$; Fig. $2 \mathrm{C})$. Change in seedling height after one year had negative relationship with increasing distance from the edge of the monodominant forest toward the mixed forest $\left(F_{1,253}=14.95\right.$, $P=0.0001$; Fig. 2B). In transects moving from the edge toward the monodominant forest, change in seedling height had no significant positive or negative relationship with distance $\left(F_{1,327}=0.62, P=0.43\right.$; Fig. 2 B $)$.

\section{Discussion}

Results of this study support the hypothesis that the common ECM network enhances ECM seedling survivorship and growth within an ECM forest. The significantly reduced growth, leaf numbers and survival of seedlings in the fine mesh treatment, indicates that ECM recruitment is enhanced with access to the common ECM network in the monodominant forest. The lack of differences between the coarse mesh treatments and the controls indicates that the observed differences were due to access to the ECM network, and not an effect of the mesh itself. Pores in the fine mesh $(0.45 \mu \mathrm{m}$ diameter pores) were large enough to enable solute passage, although the potential for water logging in this treatment was not fully explored. If water logging did occur in the fine mesh pots, this could have created the same patterns in seedling survival that were observed. However, the flow rate of this mesh is 75 $\mathrm{mL} \cdot \mathrm{min}^{-1} \cdot \mathrm{cm}^{-2}$ (Millipore, personal communication), so it is assumed that water flow blockage was not a confounding variable for this treatment. When the pots were harvested there was no evidence of external root penetration into the mesh. If roots from outside the pots were able to break the nylon mesh, then the ECM network would also have access to seedling roots inside the pots. While this should be a concern for researchers using this technique, this was not found to be problematic in this study.

The percentage of ECM colonization of the surviving seedlings after one year was near $100 \%$ for all seedlings, including those excluded from the common ECM network. Thus, exclusion from the common ECM network did not suppress ECM colonization of seedlings. This implies that sufficient inoculum is present in the soil for ECM formation on seedling roots and that a contiguous ECM mycelium is not required for root colonization. It has been suggested that ECM seedling colonization by incorporation into existing ECM mycelia is an important benefit of the ECM network (Alexander et al. 1992, Onguene and Kuyper 2002), however this was not the case for D. corymbosa seedlings. Because survival, growth and leaf numbers differed between treatments, being ECM alone is not enough for seedling advantages in this system. Evidence from this study suggests that the common ECM net functions to foster monodominance in this system by promoting enhanced seedling survival in the forest understory (see Plate 1).

One alternative explanation for the patterns found in the mesh pot experiment may that the community of ECM fungi colonizing the seedlings inside of the fine mesh pots was different than the fungi colonizing seedlings in the treatment that excluded roots and hyphae ( $0.45 \mu \mathrm{m}$ mesh pots). It is possible that the fungi able to colonize seedlings from resident spores and hyphal fragments in the soil are more carbon demanding or less "mutualistic" to seedlings compared to the ECM fungi that would result from access to the ECM network. It has been found in other systems that different ECM fungi can be placed in different functional groups (Gebauer and Taylor 1999), in that they have different capacities to acquire nutrients for their associate trees and have different carbon demands. Thus, the specific ECM fungal species that connect the seedlings to the ECM network may be more beneficial for understory seedlings than the ECM fungi that colonized the seedlings inside of the fine mesh pots. Nylon mesh bags have been used in several studies to estimate extramatrical ECM biomass (Wallander et al. 2001, Nilsson et al. 2005), but molecular identification of the taxa colonizing the bags has not been done. Thus, there is currently insufficient data on how mesh influences the ECM community (Cairney 2005).

The positive distance dependence found in the wild seedling survey is consistent with patterns expected from results of the mesh experiment, which showed that access to the common ECM network increases seedling growth and survival. Although it is unknown how expansive the ECM network is, as this will largely depend on the fungal species forming the network, the highest distance of ECM mycelia will likely be near to the base of the adult tree where the highest concentration of fine roots reside. Thus, seedlings will have greatest access to the ECM network near to the canopy adults. This does not mean, however, that positive distance dependence should always be expected in ECM systems. A lack of positive distance-dependent survival may not necessarily correspond to a lack of benefit of the ECM network, as negative distance-dependent forces such as selective herbivory and pathogen infection below conspecific adults may be stronger than the benefits of the ECM network. An example of this was found in the African ECM species Paraberlinia bifoliolata (Onguene and Kuyper 2002). Seedlings of this species were transplanted under conspecific and three non-conspecific ECM trees at various distances from the tree bases. This study also included an ECM network exclusion treatment, using PVC tubes. Paraberlinia bifoliolata seedlings had greater survival under one of the non-conspecific ECM tree compared to survival 


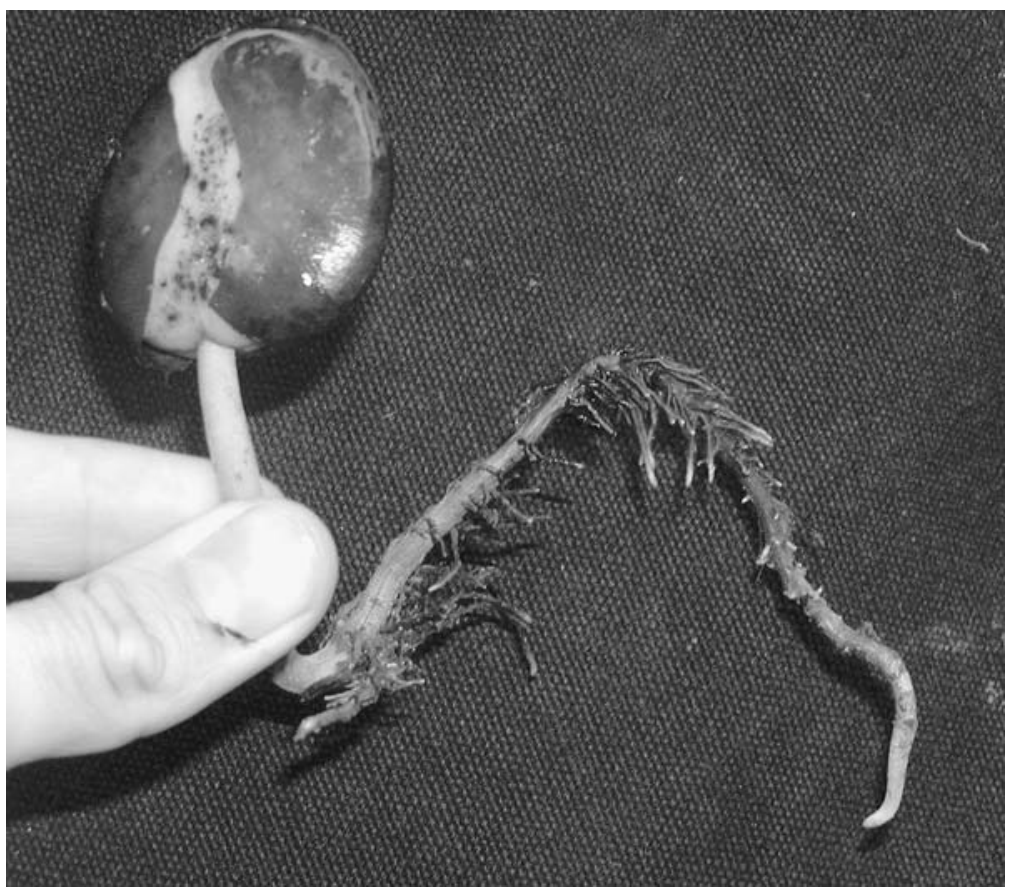

Plate 1. Newly germinated seeds, such as this one, are already ectomycorrhizal, as evidenced by the ectomycorrhizal root tips visible to the naked eye. This seedling had germinated only two days earlier and could already be benefiting from access to the common ectomycorrhizal net. Photo credit: K. McGuire

under conspecific adults. Seedling survival increased with increasing distance from the base of the nonconspecific tree, and seedlings excluded from the ECM net had significantly poorer survival with increasing distance. The authors concluded that the ECM network was probably necessary for the successful establishment of these seedlings, but that negative distance-dependent forces present near conspecific adults made seedling reliant on ECM nurse trees. It should be noted that these ECM species do not attain monodominance, which may or may not be related to the lack of positive distancedependent survival. The implication is that if adult ECM trees are supporting non-conspecific seedling establishment rather than their own progeny, then the potential for monodominance is decreased. Future studies empirically comparing the relative strengths of the benefits conferred by the common ECM network on seedling survivorship and the mortality caused by negative distance-dependent forces would provide more insight into these dynamics. By quantifying these opposing forces, predictions can be made regarding the potential of a given ECM species to maintain aggregates of monospecific forest patches.

A remaining question that has been little explored in monodominant systems is whether or not the forests are expanding, contracting or in stasis. Answers to these questions may be better examined at other life stages that may be more influential in driving canopy diversity patterns. At BCI and in Amazonia, pre-existing sapling diversity in the understory has been found to be more important for gap regeneration than seedling colonization (Uhl et al. 1988, Brokaw and Scheiner 1989). However, long-term studies of monodominance have only been conducted in the Gilbertiodendron dewevrei system in Africa. Here, researchers found over a six-year period that the monodominant forest is advancing into the mixed forest at a rate of $0.34 \mathrm{~m} / \mathrm{yr}$ (Thomas et al. 2005). At the transition zone biomass and dominance of G. dewevreii is significantly increasing in stems $\geq 1 \mathrm{~cm}$ $\mathrm{dbh}$. The authors suggest that the monodominant forest is slowly expanding and displacing the mixed species, but that large catastrophic events such as fires may prevent the indefinite spread of this species. This may also be occurring in D. corymbosa forests, as carbon has been found in some soil pit layers (K. L. McGuire, unpublished data), but long-term data on dynamics at the transition zone are not currently available.

It is probable that mechanisms other than those related to mycorrhizal associations contribute to tropical monodominance, even in ECM systems. AM species such as Pentaclethra macroloba (Hartshorn and Hammel 1994), Celaenodendron mexicanum (Martijena and Bullock 1994), and Cynometra alexandri (Torti and Coley 1999) can attain monodominance, so it is clear that other life-history attributes are responsible for dominance in these systems. Such mechanisms include extreme shade tolerance, which enables seedlings to persist in the understory for long periods of time until a light gap becomes available, superior resistance to pathogens, herbivores and seed predators relative to 
non-dominant tree species, predator satiation through masting, and modified understory conditions that inhibit the germination of heterospecific seeds (see Torti et al. 2001 for extensive review). Competition may also play a role, especially at the seedling stage when plant density can be high. ECM associations are only one component to monodominance, and future studies of their role in other tropical ECM systems such as in Africa and Asia are needed for a complete understanding of tropical monodominance.

Here, I provide support for a mechanism by which the ECM mutualism can operate to maintain low-diversity, monodominant forests. ECM associations alone cannot explain all tropical monodominance, but the results from this study provide evidence for one mechanism by which ECM trees may have recruitment advantages compared to non-ECM species. The ecological role of ectomycorrhizal fungi in tropical rain forests has been largely understudied, as have the specific mechanisms by which mycorrhizal fungi influence tropical tree diversity. This study highlights how mycorrhizal associations need to be further explored if we are to fully understand how tree diversity patterns are generated and maintained in tropical rain forests.

\section{ACKNOWLEDGMENTS}

This project was supported by the University of Michigan EEB block grant, the Latin American and Caribbean Studies graduate fellowship, and the International Institute's seminar on Global Transformations. I thank D. R. Zak, J. Vandermeer, M. M. Pierle, and G. S. Gilbert for helpful comments on earlier versions of this manuscript, and $\mathrm{K}$. Welch for statistical advice. Invaluable field assistance and logistical support were provided by Christopher Andrew, Francino Edmund, Iñigo Granzow de la Cerda, Daniel Griffith, Robert Back, Margaret and Malcolm Chana-Sue, Raquel Thomas, and the Patamona Amerindians. The Guyana Environmental Protection Agency and the Ministry of Amerindian Affairs granted research permits for this work.

\section{Literature Cited}

Alexander, I., N. Ahmad, and S. S. Lee. 1992. The role of mycorrhizas in the regeneration of some Malaysian forest trees. Philosophical Transactions of the Royal Society of London Series B-Biological Sciences 335:379-388.

Arnebrant, K., H. Ek, R. D. Finlay, and B. Soderstrom. 1993. Nitrogen translocation between Alnus glutinosa (L) Gaertn seedlings Inoculated with Frankia sp. and Pinus contorta Doug Ex-Loud seedlings connected by a common ectomycorrhizal mycelium. New Phytologist 124:231-242.

Bergemann, S. E., and S. L. Miller. 2002. Size, distribution, and persistence of genets in local populations of the late-stage ectomycorrhizal basidiomycete, Russula brevipes. New Phytologist 156:313-320.

Booth, M. G. 2004. Mycorrhizal networks mediate overstoreyunderstorey competition in a temperate forest. Ecology Letters 7:538-546.

Brokaw, N. V. L., and S. M. Scheiner. 1989. Species composition in gaps and structure of a tropical forest. Ecology 70:538-541.

Brownlee, C., J. A. Duddridge, A. Malibari, and D. J. Read. 1983. The structure and function of mycelial systems of ectomycorrhizal roots with special reference to their role in forming inter-plant connections and providing pathways for assimilate and water transport. Plant and Soil 71:433-443.
Buscott, F., J. C. Munch, J. Y. Charcosset, M. Gardes, U. Nehls, and R. Hampp. 2000. Recent advances in exploring physiology and biodiversity of ectomycorrhizas highlight the functioning of these symbioses in ecosystems. FEMS Microbiology Reviews 24:601-614.

Cairney, J. W. G. 2005. Basidiomycete mycelia in forest soils: dimensions, dynamics and roles in nutrient distribution. Mycological Research 109:7-20.

Chave, J. 2004. Neutral theory and community ecology. Ecology Letters 7:241-253.

Connell, J. H. 1971. Diversity in tropical rain forests and coral reefs. Science 199:1302-1310.

Connell, J. H., and M. D. Lowman. 1989. Low-diversity tropical rain forests: some possible mechanisms for their existence. American Naturalist 134:88-119.

Dickie, I. A., R. T. Koide, and K. C. Steiner. 2002. Influences of established trees on mycorrhizas, nutrition, and growth of Quercus rubra seedlings. Ecological Monographs 72:505-521.

Finlay, R. D., and D. J. Read. 1986a. The structure and function of the vegetative mycelium of ectomycorrhizal plants. 2. The uptake and distribution of phosphorus by mycelial strands interconnecting host plants. New Phytologist 103:157-165.

Finlay, R. D., and D. J. Read. 1986b. The structure and function of the vegetative mycelium of ectomycorrhizal plants. 1. Translocation of C-14 labeled carbon between plants interconnected by a common mycelium. New Phytologist 103:143-156.

Gebauer, G., and A. F. S. Taylor. 1999. ${ }^{15} \mathrm{~N}$ natural abundance in fruit bodies of different functional groups of fungi in relation to substrate utilization. New Phytologist 142:93-101.

Harms, K. E., S. J. Wright, O. Calderon, A. Hernandez, and E. A. Herre. 2000. Pervasive density-dependent recruitment enhances seedling diversity in a tropical forest. Nature 404: 493-495.

Hart, T. B. 1990. Monospecific dominance in tropical rain forests. Trends in Ecology and Evolution 5:6-11.

Hart, T. B., J. A. Hart, and P. G. Murphy. 1989. Monodominant and species-rich forests of the humid tropics: causes for their co-occurrence. American Naturalist 133:613633.

Hartshorn, G. S., and B. E. Hammel. 1994. Vegetation types and floristic patterns. Pages 73-89 in L. A. McDade, K. S. Bawa, H. A. Hespenheide, and G. S. Hartshorn, editors. La Selva: ecology and natural history of a neotropical rain forest. University of Chicago Press, Chicago, Illinois, USA.

He, X. H., C. Critchley, H. Ng, and C. Bledsoe. 2004. Reciprocal N ((NH4+)-N-15 or (NO3-)-N-15) transfer between non $\mathrm{N}_{2}$-fixing Eucalyptus maculata and $\mathrm{N}_{2}$-fixing Casuarina cunninghamiana linked by the ectomycorrhizal fungus Pisolithus sp. New Phytologist 163:629-640.

Henkel, T. W. 2003. Monodominance in the ectomycorrhizal Dicymbe corymbosa (Caesalpiniaceae) from Guyana. Journal of Tropical Ecology 19:417-437.

Hogberg, P., A. H. Plamboeck, A. F. S. Taylor, and P. M. A. Fransson. 1999. Natural C-13 abundance reveals trophic status of fungi and host-origin of carbon in mycorrhizal fungi in mixed forests. Proceedings of the National Academy of Sciences (USA) 96:8534-8539.

Hubbell, S., and R. Foster. 1986. Biology, chance, and history and the structure of tropical rain forest tree communities. Pages 314-329 in J. Diamond and T. J. Case, editors. Community ecology. Harper and Row, New York, New York, USA.

Janos, D. P. 1983. Tropical mycorrhizas, nutrient cycles and plant growth. Pages 327-345 in S. L. Sutton, T. C. Whitmore, and A. C. Chadwick, editors. Tropical rain forest: ecology and management. Blackwell Scientific Publications, Oxford, UK.

Janos, D. P. 1985. Mycorrhizal fungi: agents or symptoms of tropical community composition. Pages $159-174$ in R. Molina, editor. Proceedings of the 6th North American 
Conference on Mycorrhizae. Oregon State University, Corvallis, Oregon, USA.

Janzen, D. H. 1970. Herbivores and the number of tree species in tropical forests. American Naturalist 104:501-528.

Kennedy, P. G., A. D. Izzo, and T. D. Bruns. 2003. There is high potential for the formation of common mycorrhizal networks between understorey and canopy trees in a mixed evergreen forest. Journal of Ecology 91:1071-1080.

Leigh, E. G., P. Davidar, C. W. Dick, J. Puyravaud, J. Terborgh, H. ter Steege, and S. J. Wright. 2004. Why do some tropical forests have so man species of trees? Biotropica $36: 445-473$

Makana, J., T. B. Hart, D. E. Hibbs, and R. Condit. 2004. Stand structure and species diversity in the Ituri forest dynamics plots: a comparison of monodominant and mixed forest stands. Pages 159-174 in E. C. Losos and E. G. Leigh, editors. Tropical forest diversity and dynamism. University of Chicago Press, Chicago, Illinois, USA.

Martijena, N. E., and S. H. Bullock. 1994. Monospecific dominance of a tropical deciduous forest in Mexico. Journal of Biogeography 21:63-74.

McKendrick, S. L., J. R. Leake, and D. J. Read. 2000. Symbiotic germination and development of myco-heterotrophic plants in nature: transfer of carbon from ectomycorrhizal Salix repens and Betula pendula to the orchid Corallorhiza trifida through shared hyphal connections. New Phytologist 145:539-548.

Nara, K. 2006. Ectomycorrhizal networks and seedling establishment during early primary succession. New Phytologist 169:169-178.

Newberry, D. M., I. J. Alexander, and J. A. Rother. 2000. Does proximity to conspecific adults influence the establishment of ectomycorrhizal trees in rain forest? New Phytologist 147: 401-409.

Newman, E. I. 1988. Mycorrhizal links between plants: their functioning and ecological significance. Advances in Ecological Research 18:243-270.

Nilsson, L. O., R. Giesler, E. Baath, and H. Wallander. 2005. Growth and biomass of mycorrhizal mycelia in coniferous forests along short natural nutrient gradients. New Phytologist 165:613-622.

Onguene, N. A., and T. W. Kuyper. 2002. Importance of the ectomycorrhizal network for seedling survival and ectomycorrhiza formation in rain forests of south Cameroon. Mycorrhiza 12:13-17.

Redecker, D., T. M. Szaro, R. J. Bowman, and T. D. Bruns. 2001. Small genets of Lactarius xanthogalactus, Russula cremoricolor and Amanita francheti in late-stage ectomycorrhizal successions. Molecular Ecology 10:1025-1034.

Robinson, D., and A. Fitter. 1999. The magnitude and control of carbon transfer between plants linked by a common mycorrhizal network. Journal of Experimental Botany 50:913.
SAS Institute. 2005. SAS for Windows. SAS Institute, Inc., Cary, North Carolina, USA.

Simard, S. W., and D. M. Durall. 2004. Mycorrhizal networks: a review of their extent, function, and importance. Canadian Journal of Botany-Revue Canadienne De Botanique 82: $1140-1165$

Simard, S. W., D. A. Perry, M. D. Jones, D. D. Myrold, D. M. Durall, and R. Molina. 1997. Net transfer of carbon between ectomycorrhizal tree species in the field. Nature 388:579-582.

Ter Steege, H., D. Sabatier, H. Castellanos, T. Van Andel, J. Duivenvoorden, A. Adalardo de Oliveira, E. Renske, R. Lilwah, P. Maas, and S. Mori. 2000. An analysis of the floristic composition and diversity of Amazonian forests including those of the Guiana Shield. Journal of Tropical Ecology 16:801-828.

Thomas, S. C., J. Makana, T. B. Hart, J. A. Hart, R. Condit, and C. E. N. Ewango. 2005. Deterministic changes in species composition in primary forest in the Eastern Congo basin. Abstract. Ecological Society of America 90th Annual Meeting, 7-12 August 2005, Montreal Quebec, Canada. ESA, Washington, D.C., USA.

Torti, S. D., and P. D. Coley. 1999. Tropical monodominance: a preliminary test of the ectomycorrhizal hypothesis. Biotropica 31:220-228.

Torti, S. D., P. D. Coley, and T. A. Kursar. 2001. Causes and consequences of monodominance in tropical lowland forests. American Naturalist 157:141-153.

Uhl, C., K. Clark, N. Dezzeo, and P. Maquirino. 1988. Vegetation dynamics in Amazonian treefall gaps. Ecology 69: 751-763.

Valencia, R. H., H. Balslev, H. Paz, and C. G. Mino. 1994. High tree alpha-diversity in Amazonian Ecuador. Biodiversity and Conservation 3:21-28.

Vozzo, J. A., and E. Hacskayl. 1971. Inoculation of Pinus caribaea with ectomycorrhizal fungi in Puerto Rico. Forest Science 17:239-245.

Wallander, H., L. O. Nilsson, D. Hagerberg, and E. Baath. 2001. Estimation of the biomass and seasonal growth of external mycelium of ectomycorrhizal fungi in the field. New Phytologist 151:753-760.

Wright, S. J. 2002. Plant diversity in tropical forests: a review of mechanisms of species coexistence. Oecologia 130:1-14.

Wu, B. Y., K. Nara, and T. Hogetsu. 2001. Can C-14-labeled photosynthetic products move between Pinus densiflora seedlings linked by ectomycorrhizal mycelia? New Phytologist 149:137-146.

Zagt, R. J., and M. J. A. Werger. 1997. Community structure and the demography of primary species in tropical rain forest. Pages 21-38 in R. J. Zagt, editor. Tree demography in the tropical rain forest of Guyana. Tropenbos, Utrecht, Netherlands.

\section{APPENDIX}

A figure showing orientation and setup of the wild seedling transects (Ecological Archives E088-034-A1). 